\title{
Prostate cancer metastatic to the planum sphenoidale presenting as sequential bilateral vision loss
}

\author{
Binoy Yohannan, Mark Feldman* \\ Department of Internal Medicine, Texas Health Presbyterian Hospital, Dallas, Texas, United States
}

Received: June 14, 2018

Accepted: August 13, 2018

Online Published: August 15, 2018

DOI: $10.5430 /$ crim.v5n4p5

URL: https://doi.org/10.5430/crim.v5n4p5

\begin{abstract}
Metastasis to the anterior cranial fossa from solid tumors is very unusual. We describe a 72-year-old male with history of locally advanced prostate cancer who presented with sequential bilateral vision loss, initially misdiagnosed and mistreated as giant cell arteritis. Neuroimaging eventually revealed an extra-axial soft tissue mass in the planum sphenoidale exerting a pressure effect on the cisternal segments of the optic nerves. He underwent surgical excision of the mass to try to improve his vision. Biopsy results confirmed high grade metastatic adenocarcinoma of the prostate. He was started on high dose glucocorticoids and radiation therapy and his visual symptoms improved. Patients with metastatic prostate cancer can develop cranial nerve deficits secondary to metastatic involvement of the skull base. Early recognition and appropriate therapy is essential to prevent permanent neurological impairment.
\end{abstract}

Key Words: Metastatic prostate cancer, Planum sphenoidale, Vision loss

\section{INTRODUCTION}

Prostate cancer is the second leading cause of cancer-related deaths among men in the USA. Some patients have an aggressive tumor with high Gleason score that causes widespread metastatic disease, typically affecting the axial skeleton. Usually, bony metastases in prostate cancer are osteoblastic and have an indolent course. Involvement of the skull base and orbit is very rare. We describe a case of prostate cancer with metastasis to the planum sphenoidale causing sequential bilateral vision loss that was initially misdiagnosed as giant cell arteritis. To our knowledge, this is the first case of prostate cancer with metastatic disease to this unusual location.

\section{CASe presentation}

A 72-year-old Caucasian male initially had presented to the emergency department with a one-month history of progres- sive painless vision loss in left eye associated with periorbital pain. He had recently been treated with prednisone $80 \mathrm{mg} /$ day for a presumptive diagnosis of giant cell arteritis. However, a left temporal artery biopsy, done one month earlier, revealed no evidence of vasculitis. He also had had a non-contrast MRI of the brain which was negative. His vision in the left eye did not improve, and one month later he presented again, this time with worsening vision in his right eye. He denied eye/head trauma, redness, photophobia, headache, flashes, visual floaters or focal neurological deficits. He had biopsy-proven, locally-advanced adenocarcinoma of the prostate with a Gleason score of $5+5=10$ diagnosed 12 months ago. He had radical prostatectomy, followed by 35 sessions of external beam radiation therapy with a total dose of $80 \mathrm{cGy}$. He was also treated with androgen deprivation therapy (ADT) with leuprolide injections and bi-

\footnotetext{
*Correspondence: Mark Feldman, MD; Email: MarkFeldman@texashealth.org; Address: Department of Internal Medicine, Texas Health Presbyte-
} rian Hospital, Dallas, Texas, United States. 
calutamide. He had pelvic lymph node involvement causing bilateral hydronephrosis for which he underwent retrograde ureteric stent placements. He also reported $15 \mathrm{lbs}$ weight loss in the past month. His Karnofsky performance status was $80 \%$.

On physical examination, he was moderately well nourished. Vital signs were within normal limits. He had conjunctival pallor without icterus. There was no clubbing or lymphadenopathy. Ophthalmological exam of the right eye revealed visual acuity of finger counting at 1-2 feet. There was no light perception in the left. Confrontational visual field testing confirmed a full right temporal field defect with an extinguished left field. He had pulsatile and non-tender temporal arteries. Applanation tonometry and slit lamp examination were normal. Extra-ocular movements were intact in both eyes. There was a relative afferent pupillary defect in the left eye. There was no conjunctival redness, injection or chemosis. Fundoscopy revealed mild hyperemia of the optic nerves with temporal pallor in both eyes and no macular edema. The retinal vessels had normal calibre and there was no evidence of a retinal tear, hemorrhage or detachment.

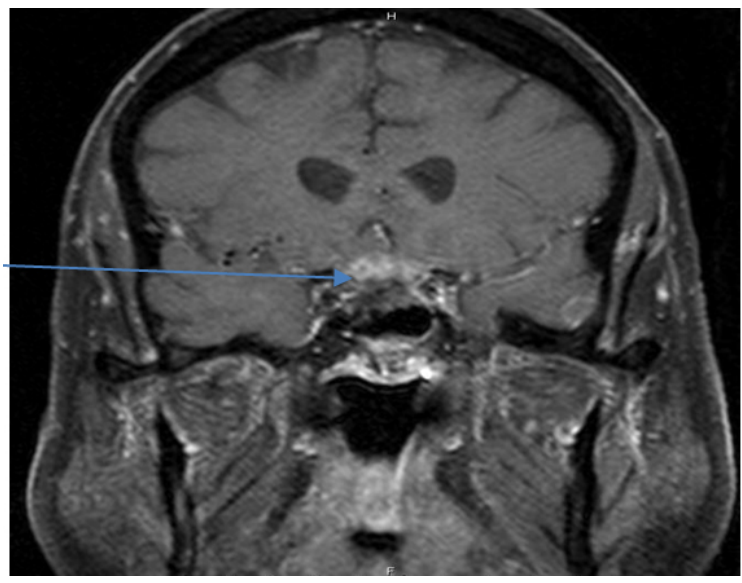

Figure 1. Mass like gadolinium contrast enhancement along the ventral sella extending superiorly and overlying the midline planum sphenoidale with mass effect (arrow) involving the inferior frontal lobes above and the cisternal segments of the optic nerves below

Complete blood count revealed a mild normocytic anemia and elevated inflammatory markers (erythrocyte sedimentation rate of $85 \mathrm{~mm} / \mathrm{hr}$ and C-reactive protein of $1.25 \mathrm{mg} / \mathrm{dl}$ ) His prostate specific antigen was considerably elevated at $97 \mathrm{ng} / \mathrm{ml}$ (reference range 0-6.5 ng/ml). CT head and MRI brain were normal. However, MRI of the face and orbits was abnormal (see Figure 1). The patient underwent left frontal craniotomy with partial orbital osteotomy and microsurgical resection of the tumor. The tumor was beefy red in appearance and completely encased both optic nerves. The frozen section biopsy was consistent with a high-grade neoplasm (see Figure 2). The patient had CT chest, abdomen and pelvis as a part of the staging work up (see Figure 3).

Postoperatively, he remained blind in the left eye. However, his vision improved in the right eye. He was started on high dose dexamethasone and radiation therapy, androgen blockage with degarelix injection ( $\mathrm{GnRH}$ receptor antagonist) and docetaxel-based chemotherapy for systemic nodal disease (see Figure 3). He deteriorated clinically after starting chemotherapy and in the light of his advanced disease, he opted to go home with hospice care and he died a few months later.

\section{Discussion}

Prostate cancer is the most common non-skin cancer among men and the second leading cause of male cancer deaths in the US. ${ }^{[1]}$ It spreads locally, hematogenously and via lymphatics to lymph nodes. Hematogenous spread occurs primarily to the axial skeleton and involves the pelvis, lumbar vertebra and ribs, frequently presenting as osteoblastic lesions. Intracerebral metastasis is a rare event (estimated incidence of $0.63 \%^{[2]}$ ) occurring hematogenously either through the arterial blood supply or via the venous route (Bateson's plexus). ${ }^{[3]}$ Cerebral metastasis usually occurs in the setting of disseminated bone and soft tissue disease and reflects a poor prognosis. ${ }^{[2]}$ Intracranial metastasis is usually seen in high grade neoplasms with Gleason scores more than 6 and is more common with the small cell variant of prostate cancer than with adenocarcinoma. ${ }^{[4]}$ The incidence of intracranial metastasis from prostate cancer is higher in autopsy studies than in antemortem studies $(4.4 \%$ vs. $0.1 \%)$ and the commonly involved structures include the leptomeninges $(67 \%)$, cerebrum $(25 \%)$, and cerebellum $(8 \%){ }^{[5]}$

Cranial nerve deficits from intracranial metastases are uncommon complications of advanced prostate carcinoma and adversely affects the patient's quality of life. Ophthalmic involvement in prostate cancer can range from bony orbital metastasis to soft tissue metastasis involving the uveal tract, extraconal space and pituitary region. ${ }^{[6-8]}$

Symptoms from intracranial metastasis depend on the structures involved and may progress over weeks to months. Serum PSA levels may not accurately reflect the extent of metastatic disease. ${ }^{[8]}$ Neurological symptoms can be secondary to tumor embolization, leptomeningeal disease, brain parenchymal lesions or from metastatic involvement of the skull base. Orbital lesions present with bony pain and proptosis while optic nerve involvement, as in our case, presents with blurring of vision and visual field defects. ${ }^{[8,9]}$ Although metastasis to the orbit, clivus, temporal bone and iris have 
been reported, this is the first case presenting with metastasis to the planum sphenoidale. Because of increased inflammatory markers, our patient was misdiagnosed initially as having giant cell arteritis and was treated unsuccessfully with glucocorticoids. Subsequently, his left temporal artery biopsy revealed no evidence of vasculitis.
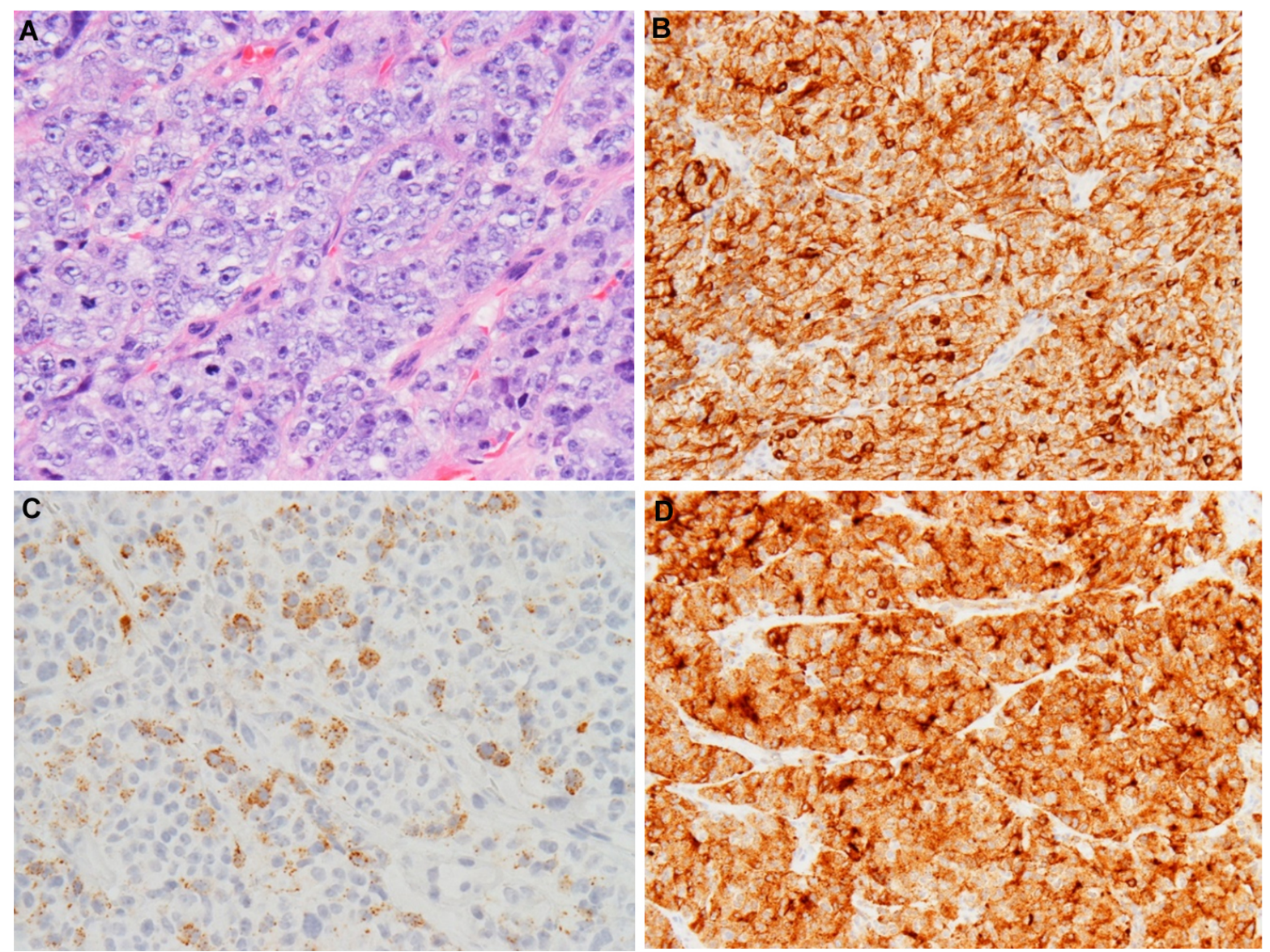

Figure 2. A. Histopathology of the resected tumor at frontal craniotomy showing a poorly differentiated neoplasm with clusters and nests of pleomorphic cells, some with prominent nucleoli. B-D. Immunohistochemistry staining showed the tumor to be positive for cytokeratin AE1/AE3, prostate specific acid phosphatase and prostate specific membrane antigen, respectively. Cytokeratin 20 stained a few positive cells. The tumor was negative for CD45, CK7, GATA-3, PSA, TTF-1, CD56 and PAX-8. The findings favored a poorly differentiated adenocarcinoma with an immunoprofile most consistent with prostatic origin.
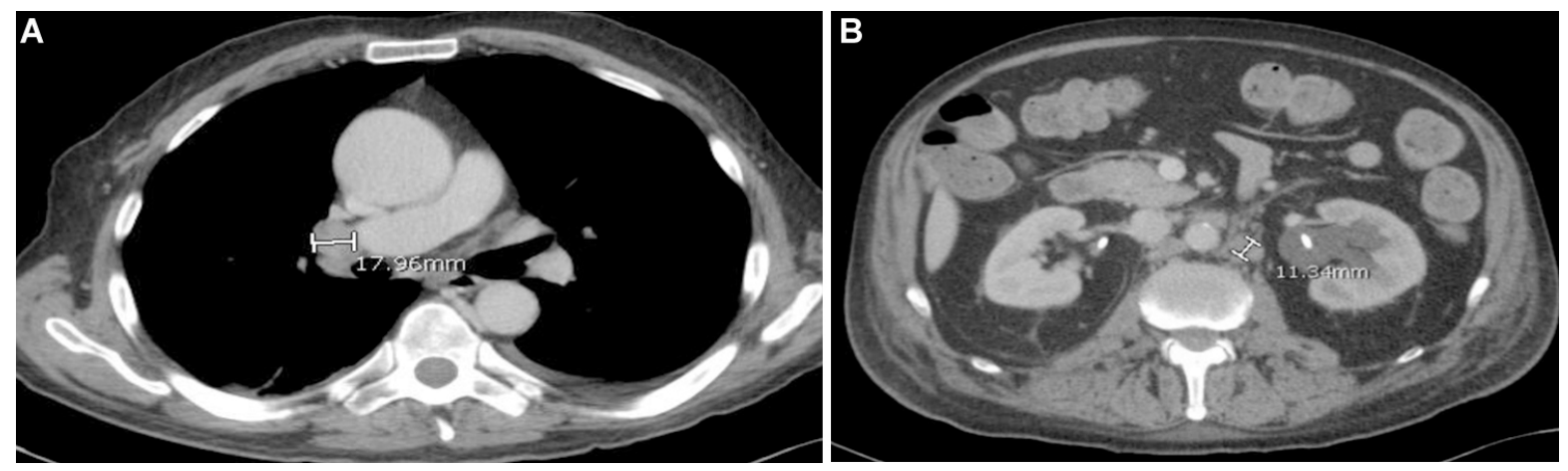

Figure 3. A. CT chest with enlarged hilar and mediastinal lymph nodes. B. CT abdomen with enlarged retroperitoneal, obturator and common iliac lymph nodes. There is persistent left hydroureteronephrosis with bilateral ureteric stents. 
Meningioma is the most common tumor arising from the anterior cranial fossa. However, metastatic disease should always be included in the differential diagnosis, especially in patients with a known cancer. CT best delineates bony disease, whereas MRI better delineates soft tissue and optic nerve involvement. Skull base tumors, especially those arising from the anterior cranial fossa above the cribriform plate and planum sphenoidale, can be easily missed on noncontrast imaging studies because of their proximity to the bone. ${ }^{10]}$ In our patient, the initial brain MRI missed the tumor because it was a non-contrast study. Hence, it is crucial to order a contrast enhanced study with orbital cuts in patients presenting with vision loss.

The numerous treatment options for men diagnosed with prostate cancer must be tailored to each individual patient based on the risk and extent of disease. For men with less aggressive disease, particularly those with PSA less than $10 \mathrm{ng} / \mathrm{ml}$ and Gleason score less than 6 , active surveillance is the preferred approach. ${ }^{[11]}$ Radical prostatectomy and radiation therapy still offer the best hope for cure in patients with localized disease. ${ }^{[11]}$ Despite the recent change in therapeutic landscape, metastatic disease remains incurable and often fatal. ADT with a GnRH agonist or antagonist remains the mainstay of systemic therapy for locally advanced and metastatic prostate cancer. ${ }^{[12,13]}$ Both GnRH agonists and antagonists can achieve castrate testosterone levels, although the main advantage of the latter is that it does so more rapidly and does not cause an initial androgen surge that can cause a disease flare. Chemohormonal therapy using docetaxel and ADT improves overall survival when compared to ADT alone in patients with hormone-sensitive metastatic prostate cancer, with the greatest benefit in patients with large volume disease. Patients progressing on ADT have an alteration in androgen receptor signalling and have defective DNA repair mechanisms and are considered castration resistant. Docetaxel improves survival in castration resistant disease and cabazitaxel has antitumor activity in docetaxel-resistant cases. Two new hormonal agents, abiraterone and enzalutamide have shown promise in castration-resistant prostate cancer. ${ }^{[12,13]}$

For patients with intracranial metastasis, treatment is aimed at control of local disease and to preserve vision. Close monitoring is appropriate in asymptomatic patients with a slow growing tumor, whereas palliative external beam radiotherapy and high dose systemic glucocorticoids are recommended to reduce perineural swelling in patients presenting with vision loss. ${ }^{[14]}$ Intracranial metastasis is associated with a poor prognosis with a median survival of one month in untreated patients. Radiotherapy and stereotactic radiosurgery improves the median survival by 3.5 months and nine months respectively. ${ }^{[2]}$ The rate of tumor growth is often dependent on androgens; hence ADT with nonsteroidal or steroidal androgen receptor blockers, GnRH inhibitors or GnRH antagonists may palliate symptoms.

\section{Conclusion}

There must be a high index of suspicion of metastatic disease to the skull base in patients presenting with cranial nerve symptoms and signs and with an underlying history of prostate cancer. This case highlights the importance of ordering appropriate studies in a patient presenting with acute vision loss. Early diagnosis and timely therapy are essential as they can prevent permanent neurological impairment.

\section{CONFlicts OF INTEREST Disclosure}

The authors declare that they have no competing interests.

\section{REFERENCES}

[1] Siegel RL, Miller KD, Jemal A. Cancer statistics. CA Cancer J Clin. 2018; 68: 7-30. PMid:29313949. https://doi.org/10.3322/ca ac. 21442

[2] Tremont-Lukats IW, Bobustuc G, Lagos GK, et al. Brain metastasis from prostate carcinoma: The M.D. Anderson Cancer Center experience. Cancer. 2003; 98: 363-8. PMid:12872358. https : //doi.org/10.1002/cncr.11522

[3] Batson OV. Function of vertebral veins and their role in spread of metastases. Ann Surg. 1940; 112: 138-149. PMid:17857618. https://doi.org/10.1097/00000658-194007000-00016

[4] Joss R, Jungi WF, Kapanci Y, et al. Extrapulmonary small-cell carcinoma - a rarity with important therapeutic consequences. Schweiz Med Wochenschr. 1984; 114: 161-166. PMid:6322292.

[5] Lynes WL, Bostwick DG, Freiha FS, et al. Parenchymal brain metastases from adenocarcinoma of prostate. Urology. 1986; 28: 280-7. https://doi.org/10.1016/0090-4295(86)90005-1

[6] Kapura S, Xiaob H. Case Report: Extraconal orbital soft tissue metastasis secondary to prostate cancer: An unusual presentation. World $\mathbf{J}$ Oncol. 2014; 5(3): 139-143.

[7] Fervenza FC, Wolanskyj AP, Eklund H. Case Report: Brain metastasis: An unusual complication from prostatic adenocarcinoma. Mayo Clin Proc. 2000; 75: 79-82. PMid:10630761. https://doi.org/ $10.4065 / 75.1 .79$

[8] Galloway G, McMullan T, Shenoy R. Rapid bilateral sequential visual loss secondary to optic canal metastases in prostatic carcinomatosis. Eye. 2003; 17: 539-40. PMid:12802364. https://doi .org/10.1 038/sj . eye 6700396

[9] Bearrick E, Uloko M, Ordonez M. Unilateral proptosis as the initial presenting sign of prostate cancer in a 45-year-old man. Urology Case Reports. 2018; 17: 15-16. PMid:29359113. https ://doi .or $\mathrm{g} / 10.1016 / \mathrm{j}$. eucr. 2017.11 .028 
[10] Wichmann W, Muller-Forell W. Anatomy of the visual system. Eur J Radiology. 2004; 49: 8-30. https://doi.org/10.1016/j.ejra d. 2003.11.001

[11] Litwin MS, Tan HJ. The diagnosis and treatment of prostate cancer: A review. JAMA. 2017; 317: 2532-2542. PMid:28655021. https://doi.org/10.1001/jama.2017.7248

[12] Quinn DI, Sandler HS, Horvath LG. The evolution of chemotherapy for treatment of prostate cancer. Annals of Oncology. 2017; 28:
2658-69. PMid:29045523. https://doi.org/10.1093/annonc $/ \mathrm{mdx} 348$

[13] Sartor O, Bono JS. Metastatic prostate cancer: Review article. N Engl J Med. 2018; 378: 645-657. PMid:29412780. https://doi. org/10.1056/NEJMra1701695

[14] Ahmed M, Begum T. Orbital metastasis from prostate cancer. BMJ Case Rep. 2015. https ://doi .org/10.1136/bcr-2015-21144 7 